\title{
Emotional Contagion and Pro-social Behavior of Student Teachers: The Mediating Effect of Moral Judgment
}

\author{
Qing Zhang, Yiya Zhang
}

Jiangsu Second Normal University, Nanjing 210013, Jiangsu, China

\begin{abstract}
Objective: To study the relationship between emotional contagion, professional behavior, and moral judgment of student teachers and the mediating role of moral judgment among them. Methods: The "Emotional Contagion Questionnaire", "Pro-social Tendencies Measure for Adolescent (PTM)" and "Moral Judgment Test (MJT)" was used to survey 448 student teachers. Results: The emotional contagion and pro-social behavior of student teachers have no significant differences between gender and urban and rural areas, but significant differences in professional nature. No significant differences were observed in moral judgment between urban and rural areas and major character, but significant in gender. A significant positive correlation was detected between emotional contagion and pro-social behavior. Conclusion: Moral judgment plays a partially mediating role in the relationship between emotional contagion and pro-social behavior.
\end{abstract}

Science Insights Education Frontiers 2021; 10(1):1341-1352.

Doi: 10.15354/sief.21.or059

How to Cite: Zhang, Q. \& Zhang, Y. (2021). Emotional contagion and prosocial behavior of student teachers: The mediating effect of moral judgment. Science Insights Education Frontiers, 10(1):1341-1352.

Keywords: Emotional Contagion, Pro-social Behavior, Student Teachers, Moral Judgment, Mediation Effect 


\section{Introduction}

7 EACHERS' emotions are one of the three sources of teaching emotions (Lu, 2006). Emotional contagion is either the student (information receiver) uncon1 sciously and automatically imitating the teacher's (information inducer) emotional state, or the student's conscious perception and regulation of emotions, through observation and capture of teachers' emotional changes, and the process of subconsciously imitating and consciously adjusting emotions together (Zhang \& Zhu,2020). Research has found that compared with novice teachers, authoritative teachers are more substantial in positive emotional contagion and weak in negative emotional contagion (Zhang et al., 2017). In social activities, negative emotions are often the driving force for adverse group incidents, inducing the occurrence and escalation of destructive incidents. Negative emotions (such as anger) are more likely to be infected in groups than positive emotions (Katz et al., 1999). However, emotional contagion will be expressed as positive emotions when the group is in a cooperative state. As a result, the group will produce a harmonious interpersonal atmosphere, and work efficiency will increase (Barsade, 2002).

Pro-social behavior is the core behavior of human beings, which often benefits others at the expense of oneself, such as helping, sharing, comforting, and voluntary activities (Penner et al., 2005). Positive emotions will induce pro-social behavior, and pro-social behavior will then maintain or restore positive emotions to form a positive feedback loop (Carlson et al., 1988). Pro-social behavior is conducive to increasing people's life happiness index. It can also shorten the distance between the individual and the social environment; making the relationship more intimate (Yang et al., 2017). Pro-social behavior is greatly affected by gender factors. Women show more pro-social behavior in non-emergency situations, whereas men show more pro-social behavior in emergencies. Men are responsible, but women pay more attention to self-evaluation and judgment by others (Ma \& Kou, 2007).

About the Author: Yiya Zhang, Department of Education and Science, Jiangsu Second Normal University, Nanjing 210013, Jiangsu, China.E-mail: yiya0628@126.com

Correspondence to: Qing Zhang, Department of Education and Science, Jiangsu Second Normal University, Nanjing 210013, Jiangsu, China. E-mail: zhangq12_0102@126.com

Funding: Jiangsu Province education science "13th Five-Year plan" "Teacher development special project" (Jc/2016/03); Foundation of Doctor Plan of Jiangsu Second Normal University (JSNU2015BZ12).

Conflict of Interests: None.

(C) 2021 Insights Publisher. All rights reserved.

Creative Commons Non Commercial CC BY-NC: This article is distributed under the terms of the Creative Commons Attribution-NonCommercial 4.0 License (http://www.creativecommons.org/licenses/bythe original work is attributed by the Insights Publisher. 
Moral judgment can predict moral behavior. Moral judgment is an inference made on the behavior of others based on the moral insights and moral knowledge that the individual currently possesses. In uncomfortable environments, such as working on a messy desk, people tend to be stricter and less tolerant of behaviors that deviate from ethics (Haidt, 2007). Emotion is an essential factor in moral judgment. The emotional state affects the moral judgment of college students. Studies have shown that moral judgment scores, when dominated by negative emotions, are higher than those for neutral or positive emotions (Wang et al., 2007). If the subjects have a more positive first impression of the protagonist of the moral event, then they will be less critical of the protagonist's behavior (Kliemann et al., 2008). There is a significant correlation between children's pro-social behavior and moral judgment level. If a person has a mature moral judgment, he is more likely to make helpful actions (Harris, 1976).

As the successor and builder of future education and teaching work, pre-service teachers' emotional quality affects moral behavior and affects students' mental health education. Because of the exceptional professional attributes of student teachers, emotional expression and transmission will affect the development of emotional quality from generation to generation in the future. The emotional quality and moral level of student teachers are related to the level of pro-social behavior from the perspective of communication and psychology. Moral judgment is not only affected by emotions but also affects pro-society. Therefore, studying the relationship between emotional contagion and professional behavior and whether a moral judgment has a mediating effect on both factors can reference student teachers to regulate their emotions and pro-social behavior and carry out education and teaching work better.

\section{Methods}

\section{Research Objects}

Student teachers from the freshman to the fourth grade were selected. A total of 496 copies were distributed in questionnaires, and 48 missing values were excluded. Finally, 448 valid questionnaires were recovered, and the effective response rate of the questionnaires was $90.32 \%$. There are 206 boys (45.98\%) and 242 girls (54.02\%); 285 $(63.62 \%)$ in urban households, $163(36.38 \%)$ in rural households; $220(49.11 \%)$ in literature and history, and $228(50.89 \%)$ in science.

\section{Research Tools}

\section{- Emotional Contagion Questionnaire}

Based on the "emotional contagion questionnaire" (Doherty 1997), it according to China's national conditions and tested its reliability and validity (Zhang et al., 2017). The questionnaire contains 25 items, divided into five dimensions: happiness, love, sadness, 
anger, and fear. All items are scored positively, using Likert 5-level scoring, with good reliability and validity.

\section{- Pro-social Tendencies Measure for Adolescent (PTM)}

Carlo et al. compiled a youth pro-social tendency scale, which was later revised (Kou et al., 2007). There are 26 questions on the scale, all of which are forward scoring questions. The scale is divided into six dimensions: altruism, compliance, openness, anonymity, emotion, and urgency. Likert 5 scoring was used, and the higher the score, the higher the pro-social tendency of the individual. The Cronbach alpha coefficient is 0.85 .

\section{- Moral Judgment Test (MJT)}

There are 26 questions in total, using Likert 9-level scoring. The test contains two preset scenarios: "factory storm" and "doctor's dilemma." Participants must first judge the rationality of what the story's protagonist did and then indicate their degree of acceptance based on the support or opposition given. The measure of moral judgment is the Competent score, which is the $\mathrm{C}$ score (1-100). According to the specific value of the $\mathrm{C}$ score, the individual's moral judgment can be divided into four levels: low $(<9$ points), medium (10-29 points), high (30-49 points), high and above (> 50 points).

\section{Data Analysis}

The statistical tool SPSS20.0 was used to conduct descriptive statistics on the data, independent sample t-test, correlation test, regression, and other data analysis methods to explore the relationship between the variables. And use Amos to verify the mediating effect of moral judgment in the relationship between emotional contagion and prosocial behavior.

\section{Results}

\section{Statistical Analysis of Emotional Contagion, Pro-social Behavior and Moral Judgment of Student Teachers}

The average emotional contagion score was 94.98. The overall difference in each dimension was not significant, among which the average score of "love" was the highest, and the average score of "sad" was the lowest. The average score for pro-social behavior is 98.10. Among them, the "anonymous" dimension had the highest average score, with an average of 18.93; the "compliant" dimension was followed closely with an average of 18.74; but the "urgent" dimension had the lowest average score, with an average of 11.32 (Table 1). 
Table 1. Descriptive Statistics of Emotional Contagion, Professional Behavior, Moral Judgment and Various Dimensions of Student Teachers.

\begin{tabular}{lllll}
\hline Variable & Mean & SD & Minimum & Maximum \\
\hline Happiness & 18.88 & 4.78 & 5 & 25 \\
\hline Love & 19.43 & 4.78 & 6 & 25 \\
\hline Fear & 18.75 & 4.64 & 5 & 25 \\
\hline Anger & 19.19 & 4.91 & 6 & 25 \\
\hline Sadness & 18.72 & 4.71 & 6 & 25 \\
\hline Emotional Contagion & 94.98 & 22.25 & 35 & 119 \\
\hline Emotional & 14.98 & 3.74 & 6 & 25 \\
\hline Compliant & 18.74 & 4.86 & 6 & 25 \\
\hline Altruistic & 14.98 & 3.74 & 4 & 20 \\
\hline Anonymous & 18.93 & 4.83 & 7 & 25 \\
\hline Public & 14.98 & 3.74 & 4 & 20 \\
\hline Urgent & 11.32 & 2.98 & 3 & 15 \\
\hline Pro-social Behavior & 98.10 & 22.90 & 38 & 124 \\
\hline Moral Judgment (C Scoring) & 18.19 & 12.00 & 1.06 & 78.91 \\
\hline
\end{tabular}

Moral judgment: the average score of $\mathrm{C}$ score was 18.19 , which was moderate (10-29 points) of moral judgment. Its median value was 15.97 , the standard deviation was 12.00 , the minimum value was 1.06 (lower level), and the maximum value was 78.91 (higher and above level). There were 120 cases $(26.79 \%)$ at a low moral judgment level; 259 cases $(57.8 \%)$ at a middle level; 57 cases at a higher level (12.72\%); 12 cases at a higher level $(2.68 \%)$.

\section{Analysis of Differences in Emotional Contagion, Pro- fessional Behavior, and Moral Judgment of Student Teachers in Gender, Urban and Rural Areas, and Pro- fessional Nature}

No significant difference was observed in the total score of emotional contagion of student teachers in gender $(\mathrm{t}=0.603, \mathrm{p}>0.05)$, and also no difference in urban and rural dimensions $(\mathrm{t}=1.251, \mathrm{p}>0.05)$. Still, a significant difference was detected in the major $(\mathrm{t}=2.244, \mathrm{p}<0.05)$.

No significant difference was shown in the total score of pro-social behavior in gender $(\mathrm{t}=0.279, \mathrm{p}>0.05)$, but significant in the urban and rural dimensions $(\mathrm{t}=1.521$, $\mathrm{p}>0.05)$, and also a significant in professional sub-discipline $(\mathrm{t}=2.494, \mathrm{p}<0.05)$.

A significant difference was observed in moral judgment between genders $(\mathrm{t}=$ $2.979, \mathrm{p}<0.01)$, and the moral judgment of girls was significantly higher than that of boys. There was no significant difference in the urban and rural dimensions $(t=0.704$, 
Table 2. The Differences of Emotional Contagion, Professional Behavior, Moral Judgment of Student Teachers in Gender, Urban and Rural Areas, and Professional Nature.

\begin{tabular}{|c|c|c|c|c|c|}
\hline Variable & Classification & Mean & SD & $\mathbf{T}$ & $\mathbf{p}$ \\
\hline \multirow[t]{2}{*}{ Emotional Contagion } & Male & 95.67 & 21.47 & 0.603 & 0.547 \\
\hline & Female & 94.39 & 22.92 & & \\
\hline \multirow[t]{2}{*}{ Pro-social Behavior } & Male & 98.43 & 22.26 & 0.279 & 0.781 \\
\hline & Female & 97.83 & 23.48 & & \\
\hline \multirow[t]{2}{*}{ Moral Judgment (C) } & Male & 16.37 & 10.98 & 2.979 & $0.003^{\star \star}$ \\
\hline & Female & 20.01 & 17.3 & & \\
\hline \multirow[t]{2}{*}{ Emotional Contagion } & Urban & 95.97 & 21.54 & 1.251 & 0.211 \\
\hline & Rural & 93.24 & 23.42 & & \\
\hline \multirow[t]{2}{*}{ Pro-social Behavior } & Urban & 99.35 & 22.22 & 1.521 & 0.129 \\
\hline & Rural & 95.93 & 23.96 & & \\
\hline \multirow[t]{2}{*}{ Moral Judgment (C) } & Urban & 18.49 & 12.04 & 0.704 & 0.482 \\
\hline & Rural & 17.66 & 11.95 & & \\
\hline \multirow[t]{2}{*}{ Emotional Contagion } & Literature and History & 97.37 & 21.13 & 2.244 & $0.025^{\star}$ \\
\hline & Science and Engineering & 92.67 & 23.10 & & \\
\hline \multirow[t]{2}{*}{ Pro-social Behavior } & Literature and History & 100.84 & 21.70 & 2.494 & $0.013^{*}$ \\
\hline & Science and Engineering & 95.47 & 23.75 & & \\
\hline \multirow[t]{2}{*}{ Moral Judgment (C) } & Literature and History & 19.38 & 12.50 & 2.079 & $0.038^{*}$ \\
\hline & Science and Engineering & 17.03 & 11.41 & & \\
\hline
\end{tabular}

Table 3. Correlation Analysis of Emotional Contagion, Pro-social Behavior, and Moral Judgment.

\begin{tabular}{llll}
\hline & Emotional Contagion & Pro-social Behavior & Moral Judgment \\
\hline Emotional Contagion & 1 & & \\
\hline Pro-social Behavior & $0.968^{* *}$ & 1 & \\
\hline Moral Judgment (C Scoring) & -0.063 & -0.051 & \\
\hline${ }^{* *} p<0.01$. & & & \\
\hline
\end{tabular}

$\mathrm{p}>0.05)$, but a significant difference was shown in the major division $(\mathrm{t}=2.079, \mathrm{p}<$ 0.05) (Table 2).

\section{Correlation Analysis of Emotional Contagion, Pro- social Behavior and Moral Judgment of Student Teach- ers}




\begin{tabular}{lllllllll}
\hline $\begin{array}{l}\text { Table 4. Regression Analysis of Emotional Contagion, Moral Judgment, and } \\
\text { Pro-social Behavior. }\end{array}$ & & & & & & & \\
\hline $\begin{array}{l}\text { Dependent } \\
\text { Variable }\end{array}$ & $\begin{array}{l}\text { Independent } \\
\text { Variable }\end{array}$ & $\mathbf{R}$ & $\mathbf{R}^{2}$ & $\mathbf{F}$ & $\mathbf{B}$ & $\mathbf{S E}$ & $\boldsymbol{\beta}$ & $\mathbf{t}$ \\
\hline $\begin{array}{l}\text { Pro-social be- } \\
\text { havior }\end{array}$ & Happy & 0.917 & 0.841 & $2,352.576$ & 15.128 & 1.765 & .011 & .549 \\
\cline { 2 - 9 } & Love & 0.967 & 0.934 & $1,572.906$ & 5.003 & 1.215 & .009 & $.034^{*}$ \\
\cline { 2 - 9 } & Fear & 0.969 & 0.939 & $1,370.585$ & 3.675 & 1.187 & .008 & .513 \\
\cline { 2 - 9 } & Angry & 0.963 & 0.927 & $1,888.592$ & 6.629 & 1.250 & .007 & .595 \\
\cline { 2 - 9 } & Sorrowful & 0.952 & 0.906 & $2,135.914$ & 8.427 & 1.412 & -.008 & .603 \\
\cline { 2 - 9 } & Moral Judgment & 0.051 & 0.003 & 1.146 & -.097 & .090 & - & .285 \\
\hline
\end{tabular}

Note: ${ }^{*} p<0.05$.

The three variables of emotional contagion, pro-social behavior, and moral judgment of student teachers were analyzed for correlation, and the correlation matrix of three variables was obtained.

There was an extremely significant positive correlation between emotional contagion and professional behavior of student teachers. But the correlation with moral judgment was not substantial (Table 3).

\section{Regression Analysis of Emotional Contagion, Pro- social Behavior and Moral Judgment of Student Teach- ers}

The dimensions of emotional contagion and moral judgment were the independent variables, and the dependent variable was pro-social behavior. Further stepwise regression analysis found a very high linear relationship between the dimension of "love" and prosocial behavior, which could explain the dependent variable to a great extent. At the same time, moral judgment had a low degree of explanation for pro-social behavior (Table 4).

\section{Analysis of the Mediating Effect of Moral Judgment of Student Teachers on Emotional Contagion and Profes- sional Behavior}

In Amos, the Bootstrap method was selected as the significance test of the mediating effect of moral judgment, and random sampling was repeated 2,000 times in the original data.

The $95 \%$ confidence interval was calculated. The standardized mediation effect value and confidence interval is a mediation path, namely "emotional contagion - moral 


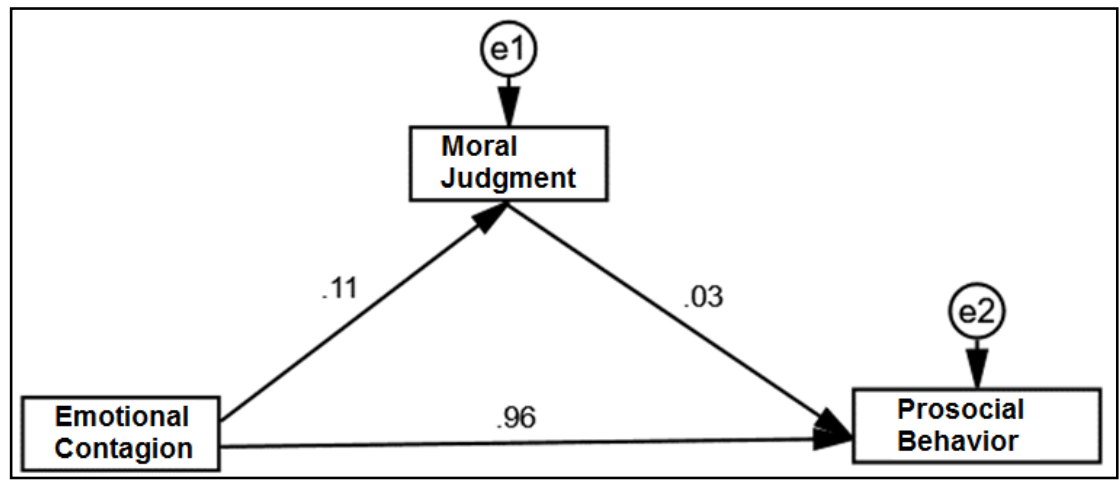

Figure 1. The Mediating Effect of Moral Judgment.

\section{Table 5. The Test Result of the Mediating Effect.}

\begin{tabular}{|c|c|c|c|c|c|}
\hline \multirow[b]{2}{*}{ Hypothesized Pathway } & \multirow[b]{2}{*}{ Effect Type } & \multirow[b]{2}{*}{ Standardization Factor } & \multirow[b]{2}{*}{ SD } & \multicolumn{2}{|c|}{$95 \% \mathrm{Cl}$} \\
\hline & & & & $\begin{array}{l}\text { Boot-Cl } \\
\text { Lower Limit }\end{array}$ & $\begin{array}{l}\text { Boot-Cl } \\
\text { Upper Limit }\end{array}$ \\
\hline \multirow{3}{*}{$\begin{array}{l}\text { Emotional Contagion- } \\
\text { Moral Judgment- } \\
\text { Pro-social Behavior }\end{array}$} & Overall Effect & 0.968 & 0.003 & 0.962 & 0.973 \\
\hline & Direct Effect & 0.965 & 0.002 & 0.957 & 0.971 \\
\hline & Indirect Effect & 0.004 & 0.003 & 0.001 & 0.008 \\
\hline
\end{tabular}

judgment—pro-social behavior.” (Figure 1).

The total effect of emotional contagion on pro-social behavior was 0.968 . The confidence interval is $[0.962,0.973]$ excluding zero, which shows that the overall effect of emotional contagion on pro-social behavior was significant. At the same time, after adding the intermediary variable (moral judgment), the direct effect of emotional contagion on pro-social behavior was 0.965 , and the confidence interval was [0.957, 0.971], excluding zero. Accordingly, emotional contagion has a significant positive impact on pro-social behavior. Further, the mediating effect value of moral judgment in the relationship between emotional contagion on professional behavior was 0.004 , and the confidence interval is [0.001, 0.008] excluding zero; that is, moral judgment plays a part of the mediating role in the relationship between emotional contagion and professional behavior (Table 5).

\section{Discussion}

We investigated the current situation of three aspects of professional behavior, emotional contagion, and moral judgment of student teachers. The results showed that the emotional contagion of student teachers had no significant difference in gender, but the 
average value of boys was higher than that of girls. There was no significant difference in the difference between urban and rural dimensions. A further investigation of emotional contagion's sub-dimension reveals a considerable difference between the "fear" in urban and rural areas, and urban students score higher than rural students. Significant differences were shown in the major sub-subjects.

Further investigation found significant differences in the major classification of happy, affectionate, angry, and sad, indicating that the scores of the students of the arts and history were significantly higher than those of the science and engineering students in these aspects. That is, liberal arts students are more capable of emotional contagion. No significant difference was observed in the total score of pro-social behavior in gender, but significant in the difference between urban and rural dimensions. Further, of all dimensions, they revealed that urban student teachers were significantly higher in the sub-dimensions of "emotional," "submissive," "altruistic," "anonymous" and "public than those from rural areas. There were also significant differences in professional subdisciplines. Among them, the scores of "emotional," "compliant," "altruistic," and "public" were significantly higher than those of science and engineering students, and there were significant differences in the "anonymous" scores. There was a very significant difference in moral judgment between genders, and the moral judgment of girls was significantly higher than that of boys. The difference in the urban and rural dimensions was not significant, but there was a significant difference in the professional subdiscipline. The data showed that students' moral judgment of literature and history was higher than science and engineering students.

A high correlation between emotional contagion and pro-social behavior in the correlation study, and emotional contagion could explain more than $90 \%$ of pro-social behavior. In contrast, the correlation between moral judgment and emotional contagion and pro-social behavior was low, and the explanation was small. In analyzing the mediating effect of moral judgment on emotional contagion and major-related behavior, moral judgment played a part in the mediating role in emotional contagion and professional behavior, and our hypothesis was verified. Emotional contagion and pro-social behavior variables have highly significant positive correlations in each dimension within and between variables. The five sub-dimensions of pro-social behavior and emotional contagion had extremely high linear relationships (all $\mathrm{R}$ values were higher than 0.9). Although related studies have not directly linked these two variables for research before, studies on the relationship between other branches of emotion and pro-social behavior had also got similar results.

For example, the path through which empathy affects pro-social behavior is that individuals have empathy due to the particular situation of others. Empathy involves empathy-like emotions related to compassion. These emotions were highly associated with pro-social feelings, and emotions trigger pro-social behavior (Zeng, 2011). There was a strong positive correlation between empathy and pro-social behavior, and data showed that the individual's empathy ability could predict pro-social behavior (Zhao et al., 2020). These results could mutually support the close relationship between emotional contagion and pro-social behavior. Our study also revealed a significant cor- 
relation between moral judgment and emotional contagion in the four sub-dimensions. Among them, a significant negative correlation was observed between moral judgment and the sub-dimension "angry." The five sub-dimensions of moral judgment and professional behavior also had a high correlation. In previous studies, similar results were received; that is, there was a significant correlation between children's pro-social behavior and moral judgment (Harris, 1976). Moral judgment predicted pro-social behavior and had a high degree of explanation (Eisenberg et al., 1983).

By analyzing the mediating role of moral judgment, we found that moral judgment plays a part in mediation between emotional contagion and pro-social behavior of students majoring in education. As an explicit behavior, pro-social behavior is bound to affect the individual's internal emotions, emotions, and perceptual judgments. Moral judgment belongs to moral cognition, which is attached to influence the moral behavior of individuals. Moreover, emotion is a factor that affects individual moral judgment. Therefore, assuming the path is established, after data analysis, the hypothesis is verified, i.e., moral judgment plays a part in the mediating role in the relationship between emotional contagion and pro-social behavior. However, the main limitation of our study is that the nature of the science subjects in the educational institutions in the sample was not obvious enough, which would inevitably weaken the difference in the results. In addition, in future research, it may be better to introduce the variable "moral emotion" that belongs to the category of emotion and feeling instead of the mediating variable of "moral judgment" for research.

According to the survey results, the following inspirations are provided for better teacher education. First of all, student teachers pay attention to the cultivation of emotional quality during school, especially the expression and experience ability of teachers' professional emotions. Allow students to receive adequate counseling and negative emotion regulation before taking up their posts, better understand the role of teachers' professional emotions, enhance the emotional appeal, and improve their prosocial behavior, which will be of great benefit to future education work. Second, since the emotional contagion scores of literature and history students are significantly higher than those of science and engineering students, science students' emotional expression ability training can be consciously strengthened. This makes it easier to perceive students' emotions in daily study and life, and can effectively pay attention to the emotional health of themselves and students. Educational institutions should provide more emotional support and guidance to relieve their pressure and appropriately express professional emotions. Third, apply the research conclusions that there is a significant positive correlation between emotional contagion and pro-social behavior, and moral judgment plays a part in the mediating role. Educational institutions pay more attention to cultivating students' moral awareness and behavior and provide students with opportunities for social practice and voluntary service to enhance pro-social behavior.

\section{Conclusions}

From the findings of the study, we draw the following conclusions: 
(i) First, the emotional contagion of college student teachers differs significantly in the major nature. Second, pro-social behavior showed significant differences in both urban and rural areas and major-related character. Third, moral judgment differs significantly in gender.

(ii) Moral judgment has a low correlation with emotional contagion and pro-social behavior. However, there is a significant positive correlation between the total score of emotional contagion and each dimension and the total score of pro-social behavior and each dimension. Meanwhile, emotional contagion explains pro-social behavior as high as $90 \%$.

(iii) Moral judgment partially mediates the relationship between emotional contagion and pro-social behavior.

\section{References}

Barsade, S.G. (2002). The ripple effect: Emotional contagion and its influence on group behavior. Administrative Science Quarterly, 47(4):644-675. DOI: https://doi.org/10.2307/3094912

Carlson, M., Charlin, V., \& Miller, N. (1988). Positive mood and helping behavior: a test of six hypotheses. Journal of Personality and Social Psychology, 55(2):211.

Doherty, R.W. (1997). The emotional contagion scale: A measure of individual differences. Journal of nonverbal Behavior, 21(2) 131154. DOI:

https://doi.org/10.1023/A:1024956003661

Eisenberg, N., Lennon, R., \& Roth, K. (1983). Prosocial development: A longitudinal study. Developmental Psychology, 19(6):846. DOI: https://doi.org/10.1037/0012-1649.19.6.846

Haidt, J. (2007). The new synthesis in moral psychology. Science, 316(5827):998-1002. DOI: https://doi.org/10.1126/science.1137651

Harris, S.R. (1976). Rational-emotive education and the human development program: A guidance study. Elementary School Guidance \& Counseling, 11(2):113-122. https://www.jstor.org/stable/42868496
Katz, J., Beach, S.R., \& Joiner Jr, T.E. (1999). Contagious depression in dating couples. Journal of Social and Clinical Psychology, 18(1):1-13. DOI: https://doi.org/10.1521/jscp.1999.18.1.1

Kliemann, D., Young, L., Scholz, J., \& Saxe, R. (2008). The influence of prior record on moral judgment. Neuropsychologia, 46(12):2949-2957. DOI: https://doi.org/10.1016/j.neuropsychologia.2 008.06 .010

Kou, Y., Hong, H.F., Tan, C., Li, L.(2007). Revision of the pro-social tendency scale for adolescents]. Psychological Development and Education, 23(1):112-117 [in Chinese]

Lu, J.M.(2006).On the emotional teaching mode. Educational Research, 4(12):55-60. [Chinese]

Ma, Y., Kou, Y. (2007). The characteristics of social information processing of pro-social and aggressive children in two hypothetical situations. Psychological Development and Education, 4(4):1-8 [Chinese]

Penner, L. A., Dovidio, J. F., Piliavin, J. A., \& Schroeder, D. A. (2005). Prosocial behavior: Multilevel perspectives. Annual Review of Psychology, 56:365-392. DOI: 
Zhang \& Zhang. Emotional Contagion and Pro-social Behavior of Student Teachers.

https://doi.org/10.1146/annurev.psych.56.09 1103.070141

Wang, Y.Q., Guo, B.Y., \& Wu, H.H. (2007).The influence of the emotional state on college students' moral judgment]. Journal of Psychological Science, 4(6):1324-1327 [in Chinese] DOI:

https://doi.org/10.16719/j.cnki.16716981.2007.06.061

Yang, Y., Li, P., Fu, X., \& Kou, Y. (2017). Orientations to happiness and subjective wellbeing in Chinese adolescents: The roles of prosocial behavior and internet addictive behavior. Journal of Happiness Studies, 18(6):1747-1762. DOI:

https://doi.org/10.1007/s10902-016-9794-1

Zeng, P.P., Yu, G.L., \& Lin, C.D. (2011).A new perspective on the research of pro-social behavior]. Educational Science, 27(1):21-26 [Chinese]
Zhang, M., Zhu, W.Q. (2020). Emotional contagion in the use of WeChat: the role of relationship closeness. Chinese Journal of Health Psychology, 28(4):548-552. [Chinese] DOI: https://doi.org10.13342/j.cnki.cjhp.2020.04. $\underline{016}$

Zhang, Q.Y., Lu, J.M., Chen, C.H., \&Yan, Z.Y. (2017).Chinese revision and reliability and validity test of emotional infection questionnaire. Psychological Exploration, 37(3):241246. [Chinese]

Zhao, H.H., Shen, L., Zheng, Q.L., \& Xu, Y.Y. (2020).Research on the relationship between empathy and pro-social behavior of college students and analysis of influencing factors]. Education and Teaching Forum, 4(29):65-67 [Chinese] 